\title{
Limites turvos, objetos fugidios, identidades inconstantes: as populações indígenas na etno-historiografia dos Andes Meridionais
}

Ricardo Cavalcanti-Schiel ${ }^{\star}$

Resumo: O presente artigo procura resenhar criticamente a produção analítica contemporânea e suas ideias força em torno da história indígena nos Andes, em particular nos chamados Andes Meridionais. Pretende também introduzir novas inquietações analíticas a partir de um caso empírico particular: o das populações das serras do contraforte oriental dessa região.

Palavras-chave: Andes. Etno-história. Etnologia. Lógicas culturais. Etnicidade.

A história da antropologia sugere-nos que o avanço do conhecimento etnológico sobre as diversas áreas etnográficas do mundo foi consideravelmente irregular. Associadas a contingências coloniais e geopolíticas das potências que tomaram a dianteira na dinâmica de produção desse tipo de conhecimento, as diversas áreas etnográficas estiveram ora umas ora outras em maior evidência nos debates da disciplina, e em certa medida informaram os problemas analíticos mais prementes desse ou daquele período. Se se tornou comum lembrar, para a o campo amazonista, que até meados da década de

\footnotetext{
* Mestre e doutor em Antropologia Social pelo Museu Nacional (UFRJ), pesquisador colaborador em nível de pós-doutorado na Unicamp e vinculado ao Laboratoire d'anthropologie sociale do Collège de France.
} 
70 do século passado a etnologia, na América do Sul, debruçava-se sobre aquele que era tido como "[...] o continente menos conhecido" (VIVEIROS DE CASTRO, 1996, p. 179), é igualmente prudente evocar o mesmo vaticínio quando tratamos da região andina. De modo análogo, também a avaliação acerca do notável crescimento da etnologia amazonista no período imediatamente seguinte é, em termos razoavelmente semelhantes, pertinente para o caso andino.

É verdade que uma larga tradição literário-documental que remonta aos primeiros tempos coloniais, assim como uma tradição americanista bem anterior (LÓPEZ-OCÓN; CHAUMEIL; VERDE, 2005), já havia investido de curiosidade intelectual a imagem de um passado pré-hispânico monumental da região. Essa curiosidade viria a fermentar com o colecionismo moderno e ilustrado de relíquias arqueológicas de um mundo exótico, que alimentou não apenas o precoce nascimento de uma arqueologia regional mas também um mercado de "arte" antiga autóctone (CABELLO, 1991; COE, 1993; BOONE, 1993). No entanto, à diferença da Mesoamérica, onde o adensamento das pesquisas etnográficas norte-americanas - a par do interesse "aplicado" por esse tipo de conhecimento, por parte do nascente indigenismo moderno local - remonta à década de 30 do século XX, nos Andes o interesse analítico por uma especificidade indígena e seus possíveis fundamentos constituintes, sejam contemporâneos (de acordo com os cânones da antropologia moderna, e para além da reiteração do estereótipo do "atraso") seja na história, tardou consideravelmente a se desenvolver e a se adensar ${ }^{1}$. Precursores houve, evidentemente, identificados por uma forte marca ensaística, como Hildebrando Castro Pozo e José Carlos Mariátegui, no Peru, ou Alcides Arguedas, na Bolívia. Da mesma forma, as aventuras difusionistas dos pioneiros antropólogos europeus, com os olhos postos naquele mesmo passado monumental, perguntavamse que influências sofrera ou exercera o "país dos incas" em tendo chegado à forma-Estado. Entretanto - e particularmente no que diz respeito aos discursos ilustrados locais - o elemento indígena nos Andes só muito tardiamente deixaria os recantos do folclore, das nostalgias de antiquário e de uma sociologia reformista condenatória, para passar para o mundo da diferença cultural. Não por acaso, há tão apenas 20 anos o reconhecido antropólogo peruano 
Juan Ossio ainda se perguntava, a título de provocação, se de fato existiam as populações indígenas andinas no Peru, no sentido de que, subsumidas discursivamente à categorização de campesinado, seria-lhes ou não reconhecida não simplesmente uma adscrição étnica específica, mas um lugar de alteridade; alteridade do sentido, do pensamento e do reconhecimento do mundo (OSSIO, 1990) ${ }^{2}$.

É nesse quadro geral de disposições (ou predisposições) intelectuais que, a partir do final da década de 60, etno-historiadores como John Murra, Tom Zuidema, Nathan Wachtel, María Rostworowski de Diez Canseco, Franklin Pease e Pierre Duviols retornam aos documentos coloniais dos primeiros tempos do contato europeu, já não mais para reconstituir as dinâmicas socioinstitucionais da administração colonial dos índios nos Andes, como fizera até então (e continuava a fazer) a historiografia clássica, fortemente orientada por uma tradição espanhola (ZAVALA, 1935; BAYLE, 1945; BELAUNDE, 1945; LOHMANN, 1957; ESPINOSA, 1960; MORENO, 1977; DÍAZ, 1977), mas para apropriar-se dos registros históricos produzidos pela administração estatal como pretextos (ou indícios) para a reconstituição de um mundo indígena orientado por sua própria lógica.

Contribuíram consideravelmente para isso (tanto quanto fez parte dos esforços dessa geração de etno-historiadores) as descobertas (ou "redescobertas") documentais, seja no gênero canônico das tradicionais crônicas históricas, as relaciones, como de outro tipo de documento, que aportava registros mais caracteristicamente etnográficos sobre as populações indígenas andinas coloniais. A hoje famosíssima Nueva Crónica y Buen Gobierno, concluída pelo nobre quéchua Guaman Poma de Ayala em 1615, descoberta por um bibliotecário alemão em 1908 na Real Biblioteca da Dinamarca e publicada pela primeira vez por Paul Rivet em 1936, já consagrarase como marco da voz indígena sobre o nascente mundo colonial, ladeando-se com a Relación de Antigüedades deste Reino del Perú, de Juan Santa Cruz Pachacuti Yamqui Salcamaygua, descoberta e publicada no final do século XIX, e servindo de contraponto à já antiga e bem conhecida crônica do "mestiço" Garcilazo de la Vega. Da mesma maneira, a primeira tradução do quéchua para o espanhol que em 1966 fizera José María Arguedas do manuscrito quinhentista de 
Limites turvos, objetos fugidios, identidades inconstantes...

Francisco de Ávila, agora intitulado Dioses y Hombres de Huarochirí, ofereceria um mapa geral e fidedigno da cosmologia e dos tropos da narrativa mítica quéchua nos primeiros tempos do contato. Seriam, no entanto, documentos burocráticos mais triviais que aportariam dados descritivos minuciosos, geograficamente bem precisados, sobre aspectos da vida quotidiana dos índios nos Andes no período posterior ou inclusive imediatamente anterior à Conquista: os autos de visitas.

O cuidadoso interesse colonial pelo controle da mão de obra tanto quanto da "alma" dos indígenas expressou-se por um notável exercício burocrático de acompanhamento, investigação e registro. A par das autoridades coloniais a quem cabiam diretamente a administração da justiça quotidiana (encomenderos e corregidores), a máquina administrativa colonial praticava uma investigação periódica, esporádica ou eventual sobre as comunidades e señoríos locais, seja com fins econômico-tributários seja com fins religiosos (inquisitoriais). $V$ isitas e revisitas eram as designações da forma específica como isso ocorria, e, sempre que ocorria, produzia um registro detalhado, "casa por casa”, como sublinhou Arguedas (apud Murra, 1968, p. 193). Assim como os autos de visitas, as expectativas dos espanhóis ao realizá-las eram muitas vezes expressas em instrucciones prévias, das quais tornou-se particularmente significativa, pela riqueza de informações etnográficas, a Instrucción para Descubrir Todas las Guacas del Perú y sus Camayos y Haciendas, do "extirpador de idolatrias" Cristóbal de Albornóz, publicada pela primeira vez por Pierre Duviols (1967).

As visitas sistematizaram-se e ganharam universalidade a partir da administração do Vice-Rei Francisco de Toledo (1569-1581), mas mesmo antes dele importantes visitas a señoríos locais haviam sido realizadas, como as de Huánuco (1562) e Chucuito (1567), publicadas respectivamente em 1967 (primeira parte) e 1964, e que acabariam contribuindo para projetar na historiografia recente uma certa percepção hispânica da autoridade indígena local e de "grupos étnicos" originais ${ }^{3}$, descuidando, curiosamente, da lógica que movia seu processo de produção: as visitas eram precedidas por instruções.

Ao tratar com um corpus documental que permitia extrair dele informações etnográficas, aquela geração de etno-historiadores não apenas se dedicou a reconstituir os fundamentos de um mundo 
indígena aparentemente perdido, mas em lançar bases interpretativas que insinuavam a persistência, na longa duração, de uma matriz cultural, que seguiria organizando as referências básicas dos indígenas contemporâneos. Não por acaso, John Murra, ao criticar os trabalhos etnográficos de Harry Tschopik sobre os Aymara de Chucuito, das proximidades do Lago Titicaca, publicados entre o final da década de 40 e início da década de 50, adverte que, mesmo que estivessem fundamentados em um extenso trabalho de campo do autor ${ }^{4}$, " [...] sua análise fica prejudicada ('handicapped') pela indisponibilidade [por então] da inspeção de 1567 do reino Lupaqa, do qual Chucuito foi a capital antes de se tornar o povoado que conhecemos" (MURRA, 1984, p. 131, tradução minha).

Ao inverter a lógica do "método regressivo", que seria posteriormente utilizado por Nathan Wachtel para a análise dos Uru do Altiplano boliviano (WACHTEL, 1990), Murra faz mais do que simplesmente lançar a sombra do passado sobre sociedades atuais. Ele insinua uma razão de inteligibilidade - antes que de simples causalidade - para os dados do presente, considerados os dados do passado. Isso reduz a mera erudição passadista as invocações inócuas que antes se faziam à imagem monumental das civilizações andinas, tanto quanto esvazia o imponderável ideológico daquilo que Métraux já havia criticado como a "miragem inca" (MÉTRAUX, 1961), incluída aí a sua apropriação pelo discurso nacionalista criollo (MÉNDEZ, 1993).

Foi apenas essa forma de superação das miragens do passado monumental que possibilitou retirar dos ombros dos indígenas andinos atuais a "sobreimagem" do decaimento (OSBORNE, 1952), do simples depauperamento, de serem, enfim, o resultado aritmético de um processo de perda histórica. Curiosamente, seria um dos alunos de John Murra, Frank Salomon, que, ao fazer um balanço parcial do notável crescimento que a etnologia andina experimentara na década de 70, inscrevendo-a agora como uma "[...] bem estabelecida subespecialidade regional da antropologia", tributaria de antemão tal avanço à "emergência de uma geração de pesquisadores de campo treinados por etno-historiadores" (SALOMON, 1982, p. 75 , tradução minha). O contexto intelectual, mais que as exigências técnicas profissionais, parece ter determinado isso ${ }^{5}$. Finalmente, se 
a etnologia amazônica encontrou no simpósio Social Time and Social Space in Lowland South American Societies, organizado por Joana Overing no $47^{\circ}$ Congresso Internacional de Americanistas - cujos papers foram publicados em 1977 - o marco das inquietações e promessas do que viria a seguir (SOUZA, 2002, p. 178), a etnologia andina o encontraria no número especial da revista Annales organizado por John Murra, Nathan Wachtel e Jacques Revel logo depois (MURRA, WACHTEL; REVEL 1978) ${ }^{6}$. Mais do que nunca, a etnologia de ambas as regiões teria agora, como horizonte de interlocução, um público internacional e novas expectativas analíticas.

O adensamento da produção andinista não se deu apenas de forma intensiva no campo da análise; foi também extensiva no espaço geográfico. E aqui introduzimos o quadro de nossas preocupações mais específicas, que se reportam a uma sub-região do mundo andino, os Andes Meridionais.

De uma parte, a considerável homogeneidade cultural ao longo da porção andina (e costeira) emoldurada historicamente pelo horizonte incaico - à diferença da flagrante diversidade amazônica - favoreceu a rápida apropriação, para uma área, de conclusões e modelos desenhados para outra. Essa observação não pretende insinuar que se estejam necessariamente traficando equívocos. Ela pretende apenas sugerir uma atenção maior (da que tem sido usualmente prestada) às diferenças de escala que as especificidades de contexto possam carrear e, finalmente, sugerir problemas analíticos que regiões específicas possam aportar para um quadro geral de suposições aparentemente pacificadas.

O que a literatura etnológica, etno-histórica e arqueológica consagraram como os Andes Meridionais é a extensão latitudinal das terras altas sul-americanas que vai do entorno do lago Titicaca, ao Norte, à região cordilheirana do que é hoje o noroeste argentino e norte chileno, ao Sul. Essa região corresponde à porção centromeridional do que um dia foi o espaço de expansão incaica, e é muito singularmente caracterizada pela aridez do seu clima (LUMBRERAS, 1981, p. 77). No entanto, historicamente, ela é bem mais complexa que essa aparente imagem unificada a um Estado central, a começar pela designação nativa que a organização estatal incaica (o Tawantinsuyu - que grosseiramente poderia ser traduzido como "a 
grande comunidade das quatro partes"7) fazia a ela: o Qullasuyu (a pronúncia aproximada em português seria "colhasuiu”), o quadrante meridional daquela "grande comunidade". (O mundo andino tem uma percepção fortemente geometrizada da relação entre partes e todo; um "todo" antes de tudo potencial, numa organização antes de tudo lógica).

Geográfica e linguisticamente, além da área aimara do Altiplano central (em torno dos $4.000 \mathrm{~m}$ sobre o nível do mar), que tende a ser reconhecida como "herdeira" do antigo Estado preincaico de Tiwanaku, os Andes meridionais são ocupados, hoje em dia, em seus bordes oriental e meridional, por um arco geográfico de língua quéchua, que, precisamente a partir do seu aspecto linguístico, pode ser em grande medida compreendido como resultado de movimentos colonizatórios patrocinados pela administração incaica. Tais movimentos caracterizaram-se por amplos transplantes populacionais, a partir dos Andes Centrais próximos a Cusco, que viriam a recobrir a antiga diversidade de gentes de variadas origens altiplânicas (e uma imponderável diversidade linguística, atualmente inexistente: aimara, puquina, uruquilha etc), cujos assentamentos se espraiavam em direção aos contrafortes de relevo movimentado e de consideráveis gradientes altitudinais (de 3.200 a 2.000m sobre o nível do mar), e se entremesclavam com outros grupos locais originais, cuja feição, hoje em dia, parece-nos ainda insondável, ao menos no estado atual dos trabalhos arqueológicos. A colonização incaica visava, no caso da conformação daquele arco quéchua, a fixação de contingentes defensivos e de ocupação agrícola, para fazer face aos grupos, subretudo guarani, das terras baixas.

Mal consolidada a colonização incaica, toda essa região foi, mais uma vez, assaltada por transtornos populacionais, dessa feita produzidos pela chegada dos espanhóis, pela depressão demográfica induzida pelas doenças a eles associadas e por sua política de massiva mobilização de mão de obra indígena para a exploração mineira, a brutal mita de Potosi. O impacto populacional da Colônia tampouco teve ou produziu uma feição homogeneizante. Como algumas províncias do contraforte oriental não estavam afetadas pela mita mineira e como aí se estabeleceram rapidamente as haciendas de espanhóis, um forte movimento migratório no primeiro século da 
Colônia ocorreu das terras altas em geral (e altiplânicas em particular) para os "refúgios" das serras orientais, que absorviam mão-de-obra indígena em condições mais amenas que o trabalho nas minas, seja nas comunidades indígenas seja mesmo nas haciendas (SÁNCHEZALBORNÓZ, 1978).

A conquista inca do Qullasuyu foi apenas parcialmente militar, e a ideia de submissão mecânica deve ser aí criteriosamente relativizada. A todas as luzes, essa conquista pareceu implicar uma permanente negociação com os chefes locais (em quéchua, kurakas), através de uma linguagem aparentemente panandina e bem conhecida: a reciprocidade distributiva (ou "redistributiva", como preferia chamá-la Murra, evocando Karl Polanyi); em que trabalho, bens, prerrogativas e símbolos de poder ocupavam níveis diferidos de produção e acumulação/distribuição, especificando autoridades e espaços de pertencimento e inclusividade. Esse mecanismo social e simbólico funcionava produzindo reiterativamente um horizonte de abertura à inclusão e à aliança. Quando chegaram os espanhóis, a linguagem lógica que sustentava tal mecanismo não se esfumou no ar, pois a inteligibilidade e a legitimidade das relações sociais eram subsidiadas por ela. Essa linguagem (a da reciprocidade distributiva) apenas passou a manejar outros termos, sob novas contingências, a ponto de vir a conformar aquilo que, do ponto de vista indígena, Tristan Platt (1982) designaria como um "pacto de reciprocidade".

De outra parte, John Murra havia proposto um modelo, ao mesmo tempo ecológico e econômico, para explicar como se conformaria a ocupação social do espaço nos Andes, em um quadro - cronologicamente suspeitado como muito antigo - de crescente complexificação e especialização. A forma mais acabada desse modelo foi apresentada em 1972, como parte do segundo volume da edição da visita de Huánuco de 1562, de cujos dados havia também se alimentado. O modelo do "controle vertical de um máximo de pisos ecológicos" (MURRA, 1972) ou modelo do "arquipélago vertical" defende fundamentalmente que o particular sucesso da ocupação humana das grandes altitudes nos Andes deveu-se à capacidade dos grupos locais estenderem, fazendo uso de suas redes de parentesco, ocupações, sazonais ou permanentes, em diversos pisos ecológicos mais baixos; "ilhas" produtivas que possibilitariam 
ao mesmo tempo a complementação da subsistência e a abundância na variedade de produtos. Isso redunda, evidentemente, num modelo de territorialidade descontínua, se é que a terrritorialidade chega a ser de fato relevante aí. Pouco depois, Murra chamou a atenção para os limites (empíricos, mais que tudo) do seu modelo, instando os arqueólogos a que eles fossem identificados e explorados, seja em termos cronológicos seja em termos geográficos (MURRA, 1977). Com efeito, em que pese o seu considerável impacto inicial, os arqueólogos tendem a reconhecer atualmente que o modelo: 1 . tem restrições temporais e geográficas; 2 . mesmo onde é aplicável não dá conta de explicar todos os fenômenos; 3. pode ser extremamente matizado; e, finalmente, 4. exige outros recursos explicativos para o entendimento de fenômenos correlatos (OWEN, 2006).

No entanto, tanto no domínio da arqueologia como no domínio da etno-história, o modelo do arquipélago produziu desdobramentos que acabaram sedimentando imagens pacíficas e até mesmo irrefletidas. De fato, Murra prendeu-se muito insistentemente na orientação vertical do seu modelo, como se ela encerrasse a totalidade das relações sociais. Seriam primeiro María Rostworowski e posteriormente Ana María Lorandi que se inquietariam com as feições e consequências por assim dizer "horizontais" da ocupação de um mesmo piso ecológico por várias "colônias", misturadas a outro grupos locais eventualmente preexistentes. A primeira, em trabalhos sobre as conformações sociais pré-hispânicas da costa do Pacífico (ROSTWOROWSKI, 1967; 1977), emprestaria às análises que se seguiram a imagem da multietnicidade; imagem a que o próprio Murra se reportaria para se aproximar descritivamente do insondável mosaico étnico-ocupacional de um território. Já a antropóloga argentina esboçaria uma hipótese mais arrojada sobre os milenares movimentos de expansão territorial de grupos locais, os assim chamados "horizontes culturais panandinos", atribuindo sua constituição à busca por hegemonia nas tensões e nos conflitos próprios à convivência de diversos arquipélagos vizinhos (LORANDI, 1977).

Os problemas não solucionados, herdados da primazia lógica da verticalidade no modelo de Murra, fizeram com que arqueólogos e etno-historiadores, sobretudo no que respeita à abordagem dos Andes Maridionais e da costa, contentassem-se pacificamente 
com a imagem fenomênica da multietnicidade, esquecendo-se de sociologizá-la, ou seja, de se perguntar como tal imagem seria possível para além de sua estaticidade mecânica e morfológica. A sedução do ineditismo que ela ofereceu parece ter-se conjugado com uma espécie de exotismo sociológico, em favor de algo como um happening da diversidade, que encantou arqueólogos e etno-

(0) historiadores. No entanto, quando deixamos o horizonte incaico e entramos na história colonial dos Andes Meridonais, as sombras de incompreensão daquele pretendido conceito descritivo se tornam mais dramáticas, particularmente frente àquele quadro logo antes apresentado de consideráveis movimentos populacionais no decurso de dois séculos, confrontado agora com os imperativos da administração espanhola de fixar e provincianizar os índios para melhor administrá-los, usando-se para isso (e esse é um dado capital) da mediação dos kurakas.

Os Andes Meridionais ingressariam mais sistematicamente no avanço da etno-historiografia andina cerca de uma década e meia depois daquela primeira geração de etno-historiadores. Se o trabalho de Nicolás de Sánchez-Albornóz (1978) lançara as bases, a partir da demografia histórica, para o entendimento das mudanças populacionais na região ao longo dos períodos colonial e republicano, movidas extrinsecamente pela pressão das demandas mineiras, tributárias e das encomiendas ${ }^{10}$, seriam, a seguir, os trabalhos de etno-historiadores com experiência etnográfica que começariam a adensar os problemas analíticos a respeito das feições sociológicas intrínsecas dos grupos indígenas dos Andes Meridionais (PLATT, 1982; BOUYSSE-CASSAGNE, 1987; BOUYSSE-CASSAGNE et alii, 1987; HARRIS et alii, 1987). Seus primeiros trabalhos já haviam comparecido ao famoso número da revista Annales, de 1978, mas foram os anos 80 que testemunharam a pujança da nova etnohistoriografia da região.

As pesquisas que se ocuparam dos grupos do Altiplano e das terras altas da cordilheira do norte de Potosi buscaram identificar as grandes unidades políticas "originais" ou ancestrais que poderiam ter produzido a miríade de comunidades (ayllus) que hoje ocupa o espaço rural dessa porção da Bolívia, em parte recorrendo à maneira como a memória indígena organiza as referências de pertencimento e 
vinculação e em parte retraçando-as sobre as pistas dos documentos históricos. A busca de um acordo entre documento e memória às vezes foi feliz, mas muitas vezes trouxe à tona sérias contradições.

O esforço por traçar "mapas étnicos originais", como o que foi realizado por Thierry Saignes (1986), cujos esquemas logo passaram a ser reiterados em profusão pelos etno-historiadores - apenas superado pelo esquema mais simples dos "señoríos aymaras" de Bouysse-Cassagne (1978, p. 1059) - se baseava na reconstituição de prováveis unidades sociais insinuadas pelos registros da administração colonial, que, por sua vez, esperava encontrar señoríos indígenas com os quais tratar, amparando-se na mediação dos seus kurakas. As presumidas "nações" indígenas recobertas pelo horizonte incaico, que agora passam a ser um tanto mecanicamente reconhecidas como "grupos étnicos", foram assim reconstruídas pela etno-história à imagem do caso paradigmático dos Lupaqa, a que Murra havia dado atenção como "reino", a partir dos autos da visita de Chucuito, de 1567. A lógica dessa geografia reconstituída seria relativamente simples: define-se um núcleo de maior densidade nas terras altas e supõe-se que, de acordo com o modelo do arquipélago, ele se espraie de forma "salpicada", em colônias, em direção à costa e/ou às serras orientais (a que a documentação colonial se refere como "valles"), constituindo "franjas [étnicas] transversais" (PLATT, 1987, p. 68). 
Limites turvos, objetos fugidios, identidades inconstantes...

"Os senhorios Aymara"

$\infty$

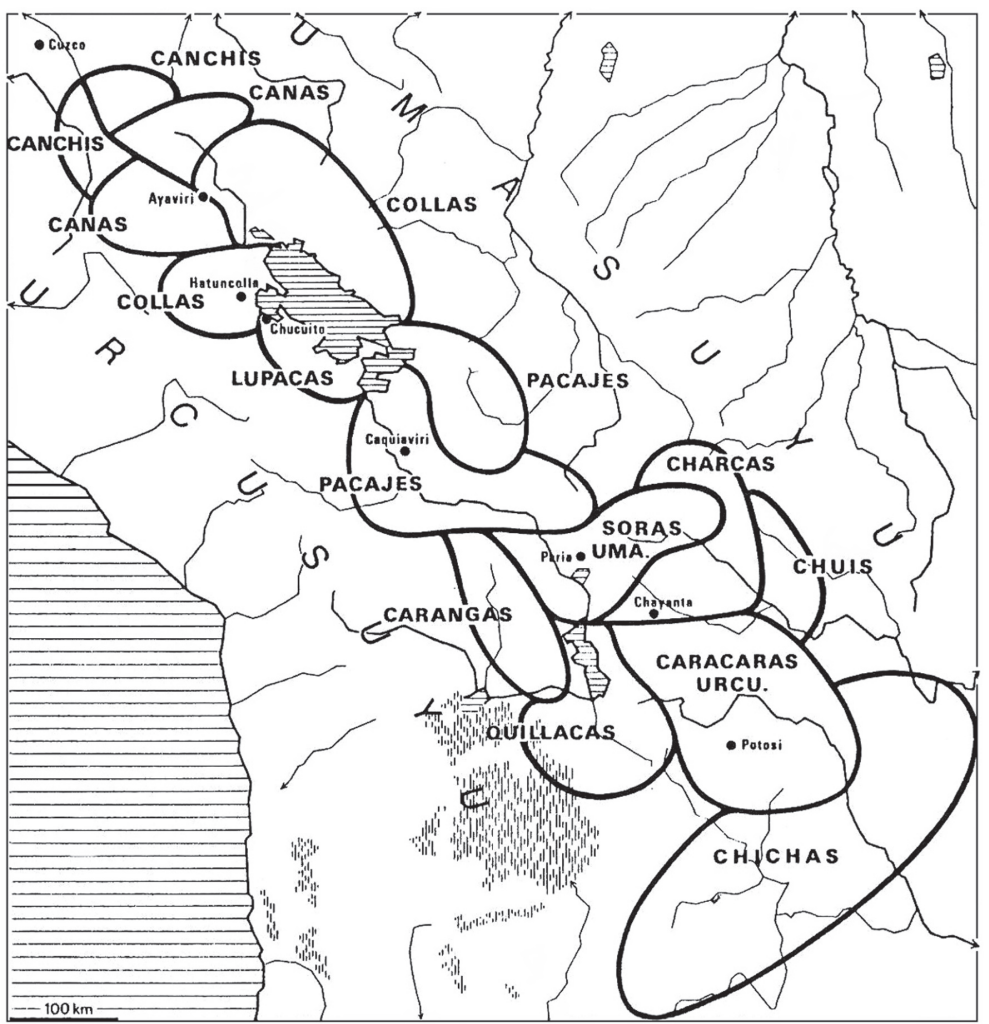

BOUYSSE-CASSAGNE, 1978, p. 1059. 


\section{"Assentamentos étnicos no século XVI"}

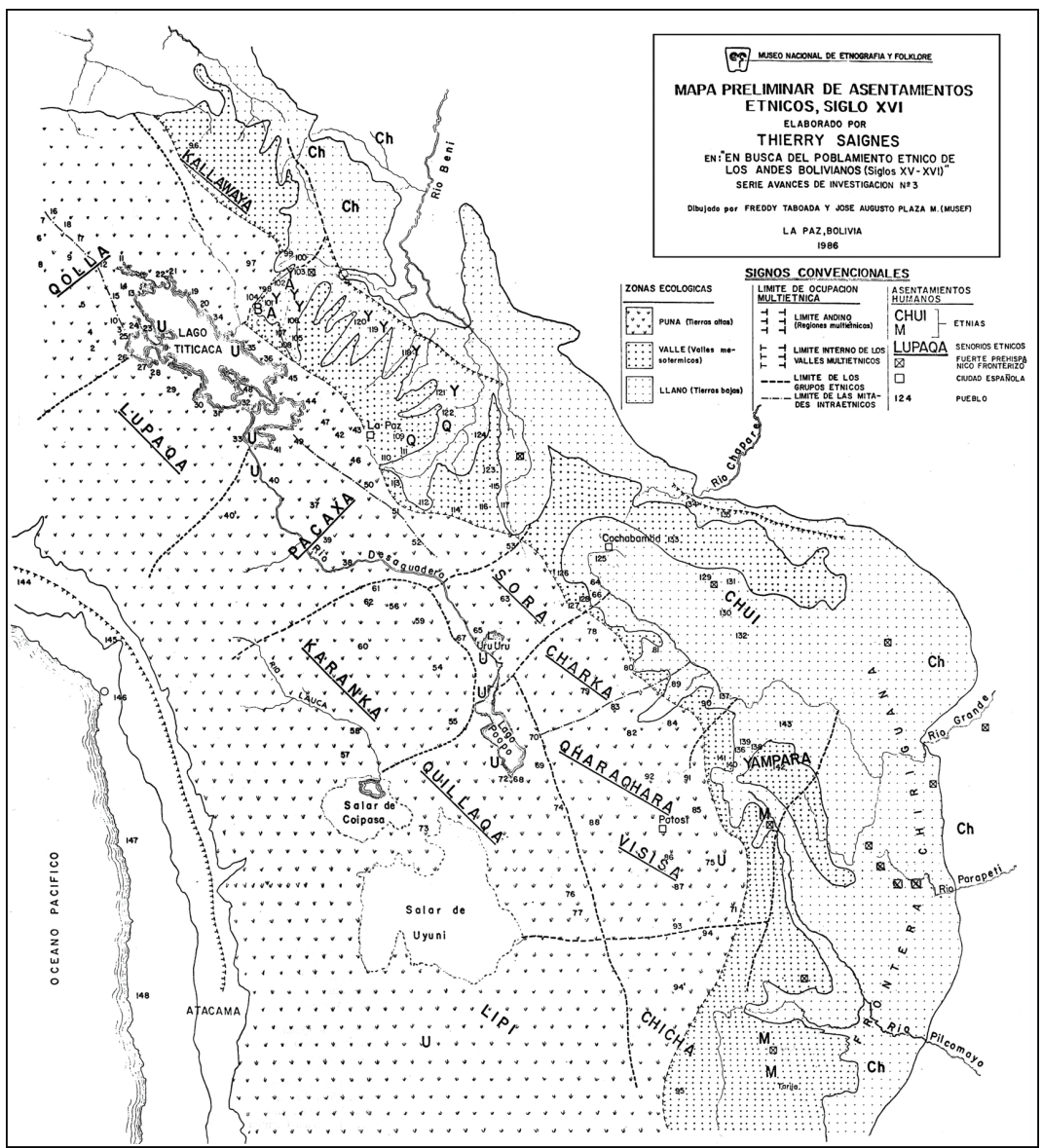

SAIGNES, 1986. 
No entanto, a situação torna-se bem mais complexa quando vêm a baila os dados etnográficos que os próprios etno-historiadores recolhem em campo, em seu duplo ofício de historiadores e etnólogos. Se no Altiplano e na puna (terras altas) de Potosi a organização social dos grupos locais parece fortemente regida por uma segmentaridade dualista (PLAT'T, 1978; 1987; RIVIÈRE, 1983; RASNAKE, 1988; IZKO, 1991; ASTVALDSSON, 2000), tal segmentaridade não responde, por outro lado, à lógica linhageira do modelo africano no qual o conceito foi originalmente produzido, e não se orienta necessariamente pelo telos de uma totalização, que, na sua acepção africana, era provido, por excelência, pela territorialidade (EVANSPRITCHARD, 1940a; 1940b). Assim, os “segmentos" - por maiores ou menores que sejam, ou seja, das unidades familiares aos ayllus máximos - são potencialmente rearranjáveis, a partir de uma outra lógica formal andina: a complementaridade gerativa das "metades" (a que Platt (1978) já se reportava por meio da categoria nativa yanantin ${ }^{11}$ ). Se a lógica formal da organização social sugere, particularmente no Altiplano e terras altas de Potosi, como defendeu Platt em termos seminais, "[...] uma continuidade fundamental entre o século XVI e a época atual" (PLATT, 1978, p. 1082), então a realização dessa lógica pode ter-se conjugado a um dispositivo que garantiu sua dinâmica, qual seja, a dinâmica do "rearranjo". Se esse dispositivo não está na linhagem, ele se encontra, a meu ver (e como tratarei adiante), na concepção andina de autoridade.

Casualmente, Olivia Harris viria a ponderar:

[...] algunas de las 'naciones' aymaras eran posiblemente creaciones de los inka, justamente para equilibrar las fuerzas regionales y crear unidades administrativas. [...] Los señoríos son precisamente las jurisdicciones de los grandes señores. Pero no hay que confundir este criterio político, derivado del sistema administrativo inka, con una supuesta identidad o homogeneidad étnica. No sabemos hasta qué punto todos los diferentes grupos que componían cada señorío se identificaban, o reconocían un parentesco común, aún después de décadas de formar parte de una misma unidad política. [...] En resumen, los problemas relacionados con el intento 
de dibujar límites incluyen él de la relación poco clara entre señoríos y grupos étnicos, tomando en cuenta que - por lo menos en el sur - los señoríos eran probablemente en parte provincias creadas por el Inka, que unían bajo un solo señor a diversas poblaciones, y que el espacio aparentemente homogéneo de cada señorío no lo era en los hechos." (HARRIS, 1997, p. 362-363).

Ora, se os indícios documentais - em especial naqueles documentos em que se registram os testemunhos das altas autoridades indígenas, envolvidas precisamente em disputas de prerrogativas, e que endereçavam ao rei suas probanz̧as de serviços e de ascendência - oferecem indícios dos rearranjos operados no contexto do horizonte incaico (JULIEN, 1983, capítulo 1), então por que os etno-historiadores das populações das punas não rastrearam até agora os rearranjos também eventualmente produzidos durante o período colonial e republicano? A meu ver isso se deve ao fato de que o regime de autoridade indígena deixou de funcionar em larga escala (CAVALCANTI-SCHIEL, 2008). Ele foi "enquadrado" pela administração colonial, que o reduziu ao utilitário da pequena escala das novas provincias. Nesse momento - e talvez apenas nesse momento - é que os grupos jurisdicionais (nesse caso, da jurisdicionalidade nativa) ganharam a fixidez morfológica que subjaz à tentação analítica de fazer deles "grupos étnicos" (WACHTEL, 1992). Esse foi um processo histórico contínuo e progressivo, que se iniciou com o estabelecimento das primeiras encomiendas e se estendeu, pelo menos, até o estabelecimento dos repartos de mercadorias sob a autoridade dos corregidores espanhóis ${ }^{12}$ - que pode ser lido também como o golpe de misericórdia nas relações de complementaridade produtiva dos diversos pisos ecológicos, regidas pelo intercâmbio recíproco. No entanto, o marco mais significativo desse processo não parece ter sido outro, no sul andino, que não o estabelecimento da mita de Potosi.

Por outro lado, para aquele que se encarrega da observação analítica, se as morfologias dualistas em alguma medida parecem reclamar uma certa fixidez, como parte de sua naturalização pelos próprios nativos - naturalização que compõe o processo de 
legitimação da ordem social -, fazendo com que certas potencialidades deixem de ser evidentes, esse não é o caso quando se trata das "multiétnicas" serras orientais, sobretudo no primeiro século da Colônia, quando, por conta das novas migrações, viram-se na contingência de receber uma enormidade de gente chegada das $p u$ nas, em geral, ao que tudo nos sugere, fugindo da mita de Potosi. E esse é, com certeza, o espaço crítico para as nossas considerações.

A documentação colonial do sul andino traz à luz um bom número de aparentes designações de grupos locais que não comparecem ao núcleo "central" (se pensarmos no modelo do arquipélago) das punas e se mostram presentes apenas nas serras orientais ${ }^{13}$ : Callahuayas, Canchis, Quiruas, Cotas, Cavis, Chuys, Yamparas, Moyo-Moyos, Churumatas, Xuríes ${ }^{14}$ - ao menos o mesmo número de designações utilizadas para as punas. À exceção dos primeiros, os assim designados Kallawaya pela literatura etnológica e etno-histórica recente (GIRAULT, 1984; RÖSING, 1991; KESSEL, 1993), essas referências foram, em geral, pouquíssimo investigadas, relegadas praticamente a uma condição marginal e quase que "culturalmente" diferenciada (BARRAGÁN, 1994) frente à imagem portentosa dos antigos señoríos aimara do Altiplano e seu sistema dualista de organização e autoridade, que recobre toda a vida ritual e a construção atual dos seus marcos de territorialidade, mesmo que aqueles grupos das serras tenham feito parte ativamente do horizonte incaico, segundo os registros que consagram o reconhecimento dos seus kurakas. Nessa condição, as serras orientais emergiram na literatura etno-histórica com as feições de uma "periferia" um tanto quanto informe, seja como a extensão do mundo das punas, passivamente aberta à colonização, seja como uma mal resolvida zona intermediária, marcada ora pelo viés altiplânico de espaços complementares e desdenhados, não obstante necessários (SAIGNES, 1985), ora pelo viés espanhol da generalidade indistinta dos "valles"15, na "fronteira"16 com as terras baixas (o espaço belicoso e indomável da "selvageria" chiriguana ${ }^{17}$ ou eventualmente, mais ao Norte, yurakaré); de qualquer forma, uma região que até bem entrada a década de 80 do século passado suscitou pouca atenção dos analistas, um domínio histórica e antropologicamente "esquecido" (ibidem). 
Seriam precisamente os trabalhos de Thierry Saignes e de seus contemporâneos ou imediatamente subsequentes (SCHRAMM, 1993; 1999; BARRAGÁN, 1994; PRESTA, 1995) que principiariam por tirar do esquecimento a história das populações indígenas das serras orientais ${ }^{18}$, que mais recentemente passaram a ser objeto de investigações arqueológicas particularmente cuidadosas (PÄRSSINEN; SIIRIÄINEN, 1998; PÄRSSINEN, 2003; ALCONINI, 2004; LIMA, 2005; RIVERA, 2005; PORTUGAL, 2006). Isso não quer dizer que um esforço analítico sistemático passou a ser investido sobre esse domínio. Ele apenas foi desvelado como objeto; o que não quer dizer que tenha sido plenamente revelado como um objeto da atenção etnológica ou, em outras palavras, como um fenômeno que possa oferecer problemas analíticos instigantes tanto para a etnologia quanto para a etno-história andinas. No entanto, é exatamente isso que talvez se possa intuir.

Associados por muitas referências documentais aos grupos das punas - o que significa que, além de estabelecerem com eles amplas relações de intercâmbio, participaram de forma consorciada em iniciativas políticas como a resistência militar ao avanço dos irmãos Gonçalo e Hernando Pizarro no sul andino em 1538 - os grupos das serras orientais pareciam compartilhar com aqueles algumas referências comuns de organização social, como a divisão de metades orientadas por "alto" e "baixo" (em quéchua, repectivamente, janan e urin) e, com ela, pelo que tudo indica, indícios de autoridade dual, ainda que sem a armadura da "segmentaridade". Que os territórios do seu entorno foram, desde muito cedo, zona de ocupação colonizatória dos grupos das punas, como reclama o modelo do arquipélago vertical, isso se insinua com certa recorrência no material arqueológico atualmente disponível. No entanto, mais do que isso, as marcas deixadas por aquilo que Murra chamou de "colônias estatais" (1972, p. 114) do horizonte incaico são não apenas ubíquas como também determinantes das feições de uma rede de adscrições múltiplas, de modo que aqui, rapidamente, os analistas lhe pespegaram o rótulo de "multiétnica".

Uma verossímil pluralidade linguística acabou recoberta pela prevalência do quéchua, mas é possível que essa prevalência só tenha se consolidado nos primeiros tempos da Colônia ${ }^{19}$. De qualquer 
Limites turvos, objetos fugidios, identidades inconstantes...

maneira, a partilha de um traço capital da lógica cultural andina parece recorrente naquilo por que os espanhóis mais se interessavam por tratar: o sistema de autoridade. E seu código fundamental não era outro que o da reciprocidade distributiva. Nas muitas probanzas de méritos e serviços que também os kurakas serranos enviavam ao rei, para que lhes fosse consagrada pela Coroa as prerrogativas da sua autoridade no âmbito da representação colonial, fica recorrentemente implícita a argumentação de que, uma vez reconhecido "gouernador" pelo Inka, era o kuraka (no caso, o ascendente daquele que encaminhava a probanza) que assentava nesses ou naqueles terrenos de cultivo esses ou aqueles índios, e a imagem trasmitida em algumas crônicas de que o Inka o fazia diretamente, tal como a evoca Olivia Harris na passagem antes citada, pode significar apenas que "ele" atribuia um kurakazgo sobre um determinado contingente, que seria assentado em uma determinada região, para que ali se produzissem determinados bens, que seriam trocados e distribuídos com a mediação desses mesmos kurakas, numa escala de prestações diferidas em que o nível mais elementar era o da prestação de trabalho (MURRA, 1987). Assim, o Inka podia ser invocado como o máximo "princípio ordenador" (OSSIO, 1973) de uma hierarquia lógica da autoridade, da mesma forma como o rei o viria a ser, diante das novas reivindicações que os kurakas agora lhe endereçavam, por meio de suas probanzas.

No caso das serras orientais, essa dinâmica foi particularmente significativa, e o foi por conta da intensidade dos movimentos populacionais, fossem deliberadamente induzidos por uma política colonizadora, fossem induzidos por uma migração quase caótica, que precisava ser de alguma forma ordenada pelas regras da existência social. Quando notei antes que, com a Conquista, o regime de autoridade indígena deixou de funcionar em larga escala, estava simplesmente indicando que a possibilidade daquela "política" deixou de existir, ou, como expressei originalmente, que o mundo indígena perdeu sua autonomia reciprocitária numa escala mais ampla (CAVALCANTI-SCHIEL, 2008, p. 108), ainda que a lógica indígena não dispusesse de outra alternativa de sentido (ou seja, de inteligibilidade do mundo) que não continuar projetando-a, já 
agora como um pacto implícito com a ordem colonial, como nos sugere Platt (1982).

De outra parte, se a autonomia reciprocitária na larga escala foi perdida, o constrangimento da pequena escala não impediu seu mecanismo de seguir funcionando. Assim, as migrações durante o período da Colônia, no sentido das punas para os valles, encontraram nos kurakazgos das provincias acolhedoras a instância de distribuição de novos recursos de existência, independente de marcas "étnicas" prévias e por mais que a pressão das haciendas se mostrasse sobre esses kurakazgos como um poderoso maquinário de expropriação de terras, produzindo batalhas judiciais que sedimentariam a imagem dos índios como "amigos de pleytos". No entanto, se os índios chegavam como "forasteros" em um corregimiento de indios, também se incorporavam como "servos dependentes" (yanakuna) nas haciendas. Ainda em meados do século XX, no momento em que se implantou a Reforma Agrária na Bolívia, os patrões das haciendas ocupavam, para os indígenas, o mesmo lugar simbólico dos antigos kurakas. Foi a lógica da reciprocidade distributiva que converteu aquelas provincias das serras orientais naquilo que chamei de uma "máquina de incorporação de gente” (CAVALCANTI-SCHIEL, 2008).

Antes disso, no horizonte incaico, ao receberem suas prerrogativas de um distribuidor frente a quem contraíam uma dívida de lealdade, os kurakas locais distribuíam, de outra parte, aos "colonizadores" (em quéchua, mitimaqkuna) terrenos de cultivo e recursos produtivos para o trabalho; trabalho que era (e continua sendo ainda hoje nos Andes) a prestação em forma de dispêndio de energia (em quéchua qallpa) que está na base de todo intercâmbio societário (CAVALCANTI-SCHIEL, 2007). Ao cederem terrenos e recursos produtivos a um grupo da puna (ou, provavelmente, melhor dito, a seu kuraka), o kuraka dos valles (ou seja, das serras) estabelecia relações de intercâmbio e firmava alianças através de uma rede que tinha como nódulos comunicantes os lugares de autoridade. Eventualmente constituía-se um dispositivo hierárquico de prerrogativas diferidas, de modo que as adscrições particulares desse ou daquele contingente eram subsumidas numa só linguagem, a da autoridade.

Desse modo, não faz muito sentido reportar-se a estanqueidades "étnicas" de pertencimento, exatamente porque o sistema 
reciprocitário é um sistema aberto, em que tudo pode ser incluído, a partir de uma gramática específica da socialidade; espanhóis, inclusive. Mas o que me interessa, para além do grande truísmo que no fundo é o enunciado logo anterior, é questionar alguns conceitos específicos (e pacíficos), e sustentar, a partir da argumentação anterior, que a estaticidade fenomênica do "multiétnico" deixa de fazer sentido, porque o que está em jogo é uma dinâmica em que as filiações podem ser permanentemente rearranjadas, contando para isso, inclusive, com os recursos do parentesco ${ }^{20}$ - o que nos levaria a ponderar mais criticamente o caráter situacional, antes que definidor, do critério da endogamia, tal como os etnólogos usualmente o utilizam, para a definição de algo como o ayllu (o grupo local) ${ }^{21}$.

Aqui chegamos, a meu ver, à dimensão "horizontal" do modelo do arquipélago, e essa pode ser a contribuição que os problemas analíticos das serras orientais (ou "valles", como se queira) - com suas imagens mais fluidas e problemáticas que o aparentemente "duro" dualismo segmentar das punas - têm a oferecer às interpretações mais gerais sobre os Andes. Olivia Harris evoca Murra, lembrando que ele "[...] há puesto em claro que no debemos suponer que cada grupo tuviera um territorio unido" (HARRIS, 1997, p. 357) ${ }^{22}$. Eu acrescentaria: tampouco fixo; ou melhor, muito escassamente se poderia falar na permanência ou reprodução histórica de cristalizações como "território" e "grupos". O "multiétnico", de outra parte, é apenas uma miragem impressionista. O que se move por trás dele, em termos de relações sociais - e aí está a "horizontalidade" - é uma lógica cultural da incorporação, ao que tudo indica, disseminada e de larga duração no mundo indígena andino. Ela se conecta a outras lógicas simbólicas, como a complementaridade gerativa de metades assimétricas (ver nota 11), a externalidade constitutiva (ver nota 21), o multinaturalismo (CAVALCANTI-SCHIEL, 2007)... Construindo permanentemente novas coerências, atribuindo inteligibilidade ao mundo e auferindo a legitimidade das relações sociais, por mais que isso tudo possa ser, em termos históricos, extremamente tenso, eventualmente contraditório e custar uma enormidade de sofrimento, pois esse é o domínio do sentido, que precede logicamente o domínio do interesse, sua pretensa lógica universal utilitarista e suas eventuais neurastenias... Étnicas. 
Finalmente, a partir das considerações anteriores, apresentadas no curso deste texto, deixo uma última apreciação sobre o modelo do arquipélago vertical, que pretende contextualizar em outros termos os seus pressupostos. A título sintético, defendo a proposição que: pode ter maior valor heurístico a hipótese de que, a partir do código cultural da reciprocidade distributiva, invertamos a causalidade estritamente econômica e ecológica que fica implícita no modelo do arquipélago, tal como ele foi postulado, ou seja: foi por disporem do código cultural da reciprocidade distributiva que os nativos dos Andes puderam realizar a complementaridade vertical de um máximo de pisos ecológicos, e não o inverso.

Se hoje as populações indígenas do sul andino estão bastante distantes, em forma, das feições dos antigos señoríos, transformadas numa nebulosa (esse sugestivo termo astronômico!) de comunidades locais, que um dos seus analistas, num esforço de síntese, pretendeu apreender sob a escala organizativa da estrita "vizinhança" (MALENGREAU, 1995), se historicamente os antigos kurakas deixaram de existir por volta do século XVIII e, finalmente, se a escala fenomênica imediata da reciprocidade distributiva reduziuse a situações e especializações sociais quase residuais, não se pode prescindir do papel histórico que ela desempenhou e de uma certa persistência do sentido, que sua lógica segue operando, seja ao perpetuar certos códigos de reconhecimento do atual poder do Estado (como "princípio ordenador"), seja ao manter a reciprocidade geral no centro da socialidade (CAVALCANTI-SCHIEL, 2007).

As populações indígenas dos Andes Meridionais - e me vejo na contingência de, por falta de melhor termo, recorrer a essa suspeita categoria biológica ("população") - ingressaram recentemente no campo de interesse das ciências humanas contemporâneas. Sua aparente alteridade pode ser, ao mesmo tempo, cômoda e traiçoeira. Elas estão presentes em cada esquina das cidades bolivianas e ocupam praticamente toda a região rural do país, onde mantêm, mesmo que de maneira enviezada, uma forma muito peculiar de ver o mundo; forma que tem uma presença histórica e que não existe apenas por que foi determinada pela "situação colonial". Suas especificidades ainda têm muito a nos inquietar e, evidentemente, nunca deixa de ser um bom exercício intelectual rever criticamente de que maneira essas 
Limites turvos, objetos fugidios, identidades inconstantes...

populações vêm sendo apreendidas e interpretadas a partir daquilo que até bem pouco tempo parecia lhes pesar como uma sombra: o passado.

\section{BLURRED BOUNDARIES, ELUSIVE OBJECTS, SHIFTING IDENTITIES: INDIGENOUS POPULATIONS IN SOUTHERN ANDEAN ETHNOHISTORIOGRAPHY}

Abstract: This paper search to review critically the contemporary analytical production on indigenous history in the Andes, and its strong ideas, specially at so called Southern Andes. It intends also to introduce new analytical concerns suggested from a specific empirical case: that from the Eastern mountain ranges of this region.

Keywords: Andes. Ethnohistory. Ethnology. Cultural logics. Ethnicity.

\section{Notas}

${ }^{1}$ Formalmente, a etnologia teve seu primeiro assento institucional nos Andes no Instituto criado por Luis Valcárcel, em 1946, na Universidad de San Marcos, em Lima. Por essa época e pelas décadas seguintes, no Peru, etnologia e arqueologia compartilhariam os mesmos espaços institucionais, e a segunda, após o período anterior dos trabalhos de alemães, franceses e de Julio Tello, o patrono da arqueologia peruana, seria consideravelmente impulsionada pelos trabalhos do norte-americano John Rowe, um dos fundadores do instituto homólogo ao de San Marcos na Universidad San Antonio Abad, de Cusco.

Entre 1952 e 1966, o projeto de antropologia aplicada desenvolvido pela universidade norte-americana de Cornell na região de Vicos proporcionou um alento considerável aos estudos de comunidade na incipiente etnologia andinista. $\mathrm{O}$ Projeto Vicos pode ser lido como uma espécie de fecundação das referências locais pelos padrões profissionais e expectativas internacionais da antropologia contemporânea, e mereceria ser confrontado com o que foi, para as terras baixas, o Projeto Harvard-Museu Nacional (1962-1967), considerando, evidentemente, que as orientações investigativas dos dois projetos foram profundamente distintas (etno-desenvolvimento naquele caso; modelos teórico-interpretativos, neste último); distinção que, por coincidência ou não (e isso merece ser objeto de um estudo mais alentado), marcaria em boa medida as tradições etnológicas dos meios acadêmicos locais de ambas as regiões. 
${ }^{2}$ Essa invocação da alteridade cultural não invalida necessariamente o que pareceria ser o seu inverso, atestado, por exemplo, por Carlos Degregori, para a longa história do contato cultural nos Andes: “[...] desde muy temprano se complejizan y matizan las oposiciones dominación/resistencia, Andes/Occidente, y se erosionan también las fronteras entre Nosotros y los Otros" (DEGREGORI, 2000, p. 29). É o próprio Degregori que sublinha, inspirado no mesoamericanista Claudio Lomnitz, a permanente tensão entre a "vontade de conhecer" e a "vontade de ignorar" o Outro.

${ }^{3}$ Confira-se, por exemplo, a leitura do próprio John Murra acerca da visita de Chucuito, expressa no artigo logo antes citado.

${ }^{4}$ Os trabalhos de Tschopik, de corte funcionalista, haviam sido enfaticamente elogiados por Weston La Barre, Allan Holmberg e Alfred Kroeber (KROEBER, 1953). Note-se que a crítica de Murra incide de uma forma muito peculiar sobre o método funcionalista do autor.

${ }^{5}$ A té nos aspectos mais técnicos da etnologia, a inspiração dos etno-historiadores da segunda metade da década de 60 se insinua. O mesmo Salomon, ao resenhar sobre a importância de uma coletânea pioneira sobre parentesco nos Andes (BOLTON; MAYER, 1977), observaria que "[...] o modelo do ayllu como uma rede de parentesco bilateral de uma profundidade de quatro gerações deve muito à exegese de Zuidema das representações precolombianas, e tem-se mostrado útil para a explicação das regras modernas de exogamia" (SALOMON, 1982, p. 80, tradução minha).

${ }^{6} \mathrm{~A}$ importância desse número da Annales pode ser também editorialmente mensurada pelo fato de sua tradução para o inglês ter produzido uma edição à parte, como livro, publicado pela Cambridge University Press, em 1986, sob o título Anthropological History of Andean Polities.

Não obstante, as novas preocupações e abordagens da etnologia andina também se manifestaram no $47^{\circ}$ Congresso Internacional de Americanistas, o Congresso do Centenário, realizado em Paris, em 1976, nos seminários organizados por Billie Jean Isbell ("Andean Symbolism") e Jorge Flores Ochoa ("Organización Social y Complementaridad Económica en los Andes Centrales), cujos papers foram publicados no mesmo ano de 1978, no volume IV das Atas do Congresso.

${ }^{7}$ Do quéchua: TAWA + NTIN + SUYU: "quatro" + sufixo inclusivo ("com... junto") + "região" (no sentido de ayllu (comunidade/família) ampliado) = "o suyu com quatro (suyus) juntos".

${ }^{8}$ Note-se que as referências empíricas do trabalho de Platt remetem-se aos séculos XIX e XX.

${ }^{9}$ Classicamente, a arqueologia distingue três horizontes andinos: o horizonte Chavín (aproximadamente de 800 a.C. a 400 a.C.), o horizonte Wari-Tiwanaku (aproximadamente de 550 d.C. a 1000 d.C.) e o horizonte Inka (de 1400 d.C. a 1532). 
${ }^{10}$ Encomienda: alocação de um contingente de mão de obra indígena a um potentado da administração colonial espanhola, para usufruir dela em seus tributos e serviços durante o período de "duas vidas" (o período de vida do favorecido pela Cédula de Encomienda e sua primeira geração de descendentes). Encerrado esse período, o contingente indígena podia ser novamente encomendado ou "posto na cabeça de Sua Majestade", que significava, nesse caso, que o favorecido com os seus tributos passava a ser a Coroa.

${ }^{11}$ Originalmente Platt defende que o conceito de yanantin se reporta a uma ideia panandina (p. 1099) de "par simétrico de igualdade perfeita", mas que pode, na verdade, "[...] servir de máscara ideológica a uma relação de fato desigual" (p. 1105). A interpretação de Platt ainda é demasiado empiricista, pois a lógica da complementaridade andina, em termos mais abstratos, supõe a participação de duas "metades" conceitualmente desiguais: homem e mulher, alto e baixo, sangue e sêmen, este mundo (kay pacha) e o outro mundo (ukhu pacha). Toda a noção andina de reprodução parece repousar sobre o esquema formal dessa relação lógica, daí eu acrescentar que se trata de uma complementaridade gerativa de metades assimétricas, em lugar do simples "dualismo". Toda a possibilidade de reprodução, nos Andes, enseja a percepção de algo que seja dual, assimétrico e complementar. A singularidade é estéril. Por ser "gerativa", a complementaridade de "metades" só se justifica pela presença lógica de um terceiro elemento: a totalização que dela resulta. Com esse terceiro elemento logicamente necessário a ideia estrita de um dualismo fica comprometida, aproximando-se mais a um modelo triádico (HARRIS, 1978). De todo modo, aquela totalização parcial é ainda passível de entrar como "metade" de uma outra relação complementar, e assim sucessivamente. Por isso, em lugar de um dualismo segmentar, preferi sugerir na minha etnografia sobre os Tarabuco (CAVALCANTI-SCHIEL, 2005) um modelo fractal. ${ }^{12}$ Os abusos a que deram origem os repartos de mercancias, foram, como sabemos, um dos principais detonadores das grandes rebeliões indígenas da década de 80 do século XVIII.

${ }^{13}$ Deixo de lado aqui, propositadamente (mas apenas por uma questão prática), a porção sul daquilo que vinha chamando de "arco quéchua" dos Andes Meridionais, ou seja a porção da província colonial de Tucumán, que hoje constitui o noroeste argentino.

${ }^{14}$ Preferi manter aqui as grafias mais usuais com que surgem na documentação, já que é a ela que me reporto, evitando a grafia "restituída" (que faz uso da redução fonética usada para o quéchua e o aimara) com que Thierry Saignes (1986, p. 46) pretendia designar "grupos étnicos".

${ }^{15} \mathrm{O}$ termo hispânico "valles", tal como se consagrou na documentação histórica para designar a região, remete-se não apenas à especificidade do relevo dos vales mesotérmicos intercordilheiranos, mas à totalidade de um vasto terreno 
extremamente movimentado, onde os vales propriamente ditos sulcam as serras do contraforte da Cordilheira, que, ainda assim, chegam a alcançar platôs de 3.200 e picos de 3.600 metros sobre o nível do mar.

${ }^{16}$ O termo "frontera" foi consagrado pela documentação administrativa e literária espanhola para designar a frente de expansão da efetiva jurisdição territorial colonial, cujo avanço se fazia pela guerra contra os índios das terras baixas.

${ }^{17}$ Os Chiriguano constituiam o primeiro grupo guarani das terras baixas, e não foram inteiramente dominados senão no final do século XIX.

${ }^{18}$ Esses trabalhos haviam sido precedidos por um único artigo avulso de Wachtel (1981).

${ }^{19}$ As dinâmicas de intercâmbio linguístico tanto com as terras mais altas quanto com as terras mais baixas são escassamente insinuadas pela documentação, mas suficientes para fazer suspeitar de algumas ocorrências inusitadas, como a possível existência de uma unidade linguística entre um desses grupos, os Chuy, e os Yurakaré, um grupo das terras baixas hoje falante de uma língua isolada (SCHRAMM, 1993, p. 23). Para Schramm, essa unidade poderia ter persistido até o período toledano.

${ }^{20}$ É bem conhecido, por exemplo, o fenômeno da cessão de ñustas ("princesas") em casamento, que o Inka fazia aos novos aliados, em geral já derrotados em batalha. ${ }^{21}$ Sobre a "externalidade constitutiva" das lógicas andinas, consulte-se por exemplo minha etnografia sobre os Tarabuco (CAVALCANTI-SCHIEL, 2005), uma das populações indígenas atuais das serras orientais, na região de Sucre, Bolívia. ${ }^{22}$ E continua: "Más bien habría que enfocar los lazos de autoridad y de dependencia que unían a pueblos que muchas veces se encontraban dispersos en un teritorio muy amplio, compartido con otros grupos". (ibidem).

\section{Referências}

ALCONINI, Sonia. The Southeastern Inka Frontier against the Chiriguanos: Structure and Dynamics of the Inka Imperial Borderlands. In: Latin American Antiquity. v. 15, n. 4, 2004, p. 389-418.

ASTVALDSSON, Astvaldur. Las voces de los wak'a. Fuentes principales del poder político Aymara. La Paz: Centro de Investigación y Promoción del Campesinado (CIPCA), 2000.

BARRAGÁN ROMANO, Rossana. ¿Indios de arco y flecba? Entre la historia y la arqueología de las poblaciones del norte de Chuquisaca (siglos XV-XVI). Sucre: Fundación Antropólogos del Surandino (ASUR), 1994. 
Limites turvos, objetos fugidios, identidades inconstantes...

BAYLE, Constantino. El protector de indios. Sevilha: Escuela de Estudios Hispano Americanos. (Separata de: Anuario de Estudios Americanos II: 1-175), 1945.

BELAUNDE GUINASSI, Manuel. La encomienda en el Perú. Lima: Mercurio Peruano, 1945.

BOLTON, Ralph; MAYER, Enrique (Eds.). Andean Kinship and Marriage. Washington: American Anthropological Association. (Special Publications n ${ }^{\circ}$ 7). 1977.

BOONE, Elizabeth Hill. Collecting the Pre-Columbian Past: Historical Trends and Process of Reception and Use. In: Elizabeth Hill Boone (Ed.). Collecting the Pre-Columbian Past. p. 315-350. Washington: Dumbarton Oaks Research Library and Collection. 1993.

BOUYSSE-CASSAGNE, Thérèse. L'espace aymara: urco et uma. In: Annales ESC. v. 33, n. 5-6, 1978, p. 1057-1080.

. La identidad aymara. Aproximación histórica (siglo XV, siglo XVI). La Paz:

Hisbol/Institut français d'études andines (IFEA), 1987.

BOUYSSE-CASSAGNE, Thérèse; HARRIS, Olivia; CERECEDA, Verónica; PLATT, Tristan. Tres reflexiones sobre el pensamiento andino. La Paz: Hisbol, 1987.

CABELLO CARRO, Paz. Las colecciones peruanas en España y los inicios de la arqueología andina en el siglo XVIII. In: Paz Cabello Carro (Ed.). Los Incas y el Antiguo Perú. 3000 Años de Historia tomo I: 466-485. Madrid/Gent: Sociedad Estatal Quinto Centenario/Imschoot, 1991.

CAVALCANTI-SCHIEL, Ricardo. Da relutância selvagem do pensamento. Memória social nos Andes Meridionais. Rio de Janeiro: PPGAS- Museu Nacional- UFRJ. Tese (Doutorado). 2005.

. Las muchas naturalezas en los Andes in Periferia 7. 2007. Disponível em: <http://ddd.uab.cat/pub/periferia/18858996n7a10.pdf>. Acesso em: 30 de out. 2011.

. Por qué los Tarabuco no son descendientes de los Yampara. In: Anuario de Estudios Bolivianos, Archivisticos y Bibliográficos del Archivo y Biblioteca Nacionales de Bolivia 2008, p. 99-141. Disponível em: < http://unicamp.academia.edu/RicardoCavalcantiSchiel/Papers/1483239/Por_que_los_Tarabuco_no_son_descendientes_de_los_Yampara>. Acesso em 30 de out. 2011.

COE, Michael D. From Huaquero to Connoisseur: The Early Market in PreColumbian Art. In: Elizabeth Hill Boone (Ed.). Collecting the Pre-Columbian Past. 271-289. Washington: Dumbarton Oaks Research Library and Collection, 1993.

DEGREGORI, Carlos Iván. Panorama de la antropología en el Perú: del estudio del Otro a la construcción de un Nosotros diverso. In: DEGREGORI, Carlos 


\section{Ricardo Cavalcanti-Schiel}

(Ed.). No hay país más diverso. Compendio de antropología peruana. Lima: Pontificia Universidad Católica del Perú/Universidad del Pacífico/Instituto de Estudios Peruanos. 2000, p. 20-73.

DÍAZ REMENTERÍA, C. J. El Cacique en el Virreinato del Perú: Estudio Histórico-Jurídico. Sevilla: Publicaciones de la Universidad de Sevilla. (Seminario de antropología americana 15). 1977.

DUVIOLS, Pierre. Un inédit de Cristóbal de Albornoz: La Instrucción para descubrir todas las guacas del Pirú y sus camayos y haziendas. In: Journal de la Société des Américanistes LVI: p. 7-39. 1967.

ESPINOZA SORIANO, Waldemar. El alcalde mayor indígena en el virreinato del Perú. Sevilha: Escuela de Estudios Hispano Americanos. (Separata de: Anuario de Estudios Americanos XVII, p. 183-300). 1960.

EVANS-PRITCHARD, Edward E. The Nuer: A Description of the Modes of Livelihood and Political Institutions of a Nilotic People. Oxford: Clarendon Press. 1940a.

. The Nuer of the Southern Sudan. In: M. Fortes; E. E. Evans-Pritchard (Eds.). African Political Systems. Londres: Oxford University Press. 1940b, p. 272-296.

GIRAULT, Louis (Ed.). Kallawaya. Guériseurs itinérants des Andes. Paris: Éditions de l'ORSTOM. (Collection Mémoires n. 107). 1984.

HARRIS, Olivia. De l'asymétrie au triangle. Transformations symboliques au nord de Potosi. In: Annales ESC. v. 33, n. 5-6, p. 1108-1125. 1978.

. Los límites como problema: mapas etnohistóricos de los Andes bolivianos. In: Thérèse Bouysse-Cassagne (Ed.). Saberes y memorias en los Andes. Paris/ Lima: Institut des hautes études de l'Amérique Latine (IHEAL)/ Institut français d'études andines (IFEA). 1997, p. 351-373.

HARRIS, Olivia; LARSON, Brooke; TANDETER, Enrique (Orgs.). La participación indigena en los mercados surandinos. Estrategias y reproducción social. Siglos XVI a XX. Cochabamba: Centro de Estudios de la Realidad Económica y Social (CERES). 1987.

IZKO, Xavier. Poderes ambiguos: Ecología, política y ritual en el Altiplano Central de Bolivia. In: URBANO, Henrique (Ed.). Poder y violencia en los Andes: 299-339. Cusco: Centro de Estudios Regionales Andinos Bartolomé de Las Casas. 1991.

JULIEN, Catherine J. Hatunqolla. A View of Inca Rule from the Lake Titicaca Region. Berkeley: University of California Press. (University of California Publications in Anthropology n. 15). 1983. 
Limites turvos, objetos fugidios, identidades inconstantes...

KESSEL, Juan van. La senda de los Kallawayas. Puno: CIDAS. 1993.

KROEBER, Alfred L. Tschopik's Aymara of Chucuito, Peru. I, Magic. In: American Anthropologist. v. 55, n. 4, p. 613. 1953.

LIMA T., Ma. del Pilar. Inkas y Yamparas... La hegemonía de poder en el norte de Chuquisaca: Los acontecimientos de Quila-Quila. La Paz: Universidad Mayor de San Andrés. (Textos Antropológicos no 16). 2005.

LOHMANN VILLENA, Guillermo. El corregidor de indios en el Perú bajo los Austrias. Madrid: Ediciones Cultura Hispánica. 1957.

LÓPEZ-OCÓN, Leoncio; CHAUMEIL, Jean-Pierre; VERDE CASANOVA, Ana (Orgs.). 2005. Los americanistas del siglo XIX. La construcción de una comunidad cientifica internacional. Madrid/Frankfurt: Iberoamericana/Vervuet.

LORANDI, Ana María. [1977] 2003. Arqueología y Etnohistoria: hacia una visión totalizadora del mundo andino. In: Anti 4 (5). Disponível em: <http://www. anticip.com.ar/CUERPO/lorandi.htm> Acesso em 30/10/2011.

LUMBRERAS, Luis G. Arqueología de la América Andina. Lima: Editorial Milla Batres. 1981.

MALENGREAU, Jacques. Sociétés des Andes. Des empires aux voisinages. Paris: Karthala. 1995.

MÉNDEZ, Cecilia. Incas sí, indios no: apuntes para el estudio del nacionalismo criollo en el Perú. Lima: Instituto de Estudio Peruanos. (Documentos de Trabajo $\mathrm{n}^{\circ}$ 56). 1993.

MÉTRAUX, Alfred. Les Incas. Paris: Éditions du Seuil. 1961.

MORENO CEBRIÁN, Alfredo. El corregidor de indios y la economía peruana del siglo XVIII. Madrid: Consejo Superior de Investigaciones Científicas/Instituto Gonzalo Fernández de Oviedo. 1977.

MURRA, John. Un reino aymara en 1567. In: MURRA, John. Formaciones económicas y políticas del mundo andino. Lima: Instituto de Estudios Peruanos. [1968] 1975, p. 193-223.

. El control vertical de un máximo de pisos ecológicos en la economía de las sociedades andinas. In: John Murra. Formaciones económicas y políticas del mundo andino. Lima: Instituto de Estudios Peruanos (IEP). [1972] 1975, p. 59-115.

. Los límites y las limitaciones del 'archipiélago vertical' en los Andes. In: John Murra. El Mundo Andino. Población, medio ambiente y economía. Lima: Fondo Editorial de la Pontificia Universidad Católica del Perú/Instituto de Estudios Peruanos (IEP). [1977] 2002, p. 126-131. 


\section{Ricardo Cavalcanti-Schiel}

. Andean Societies. In: Annual Review of Anthropology. v. 13, p. 119-141, 1984. . 1987. ¿Existieron el tributo y los mercados antes de la invasión europea? In: HARRIS, Olivia; LARSON, Brooke; TANDETER, Enrique (Orgs.). La participación indígena en los mercados surandinos. Estrategias y reproducción social. Siglos XV I a XX: 51-61. Cochabamba: Centro de Estudios de la Realidad Económica y Social (CERES).

MURRA, John; WACHTEL, Nathan; REVEL, Jacques (Eds.). Anthropologie historique des sociétés andines. Annales ESC. v. 33, n. 5-6 (Número spécial). (Paris: CNRS/École des hautes études en sciences sociales). 1978.

OSBORNE, Harold. Indians of the Andes: Aymaras and Quechuas. London: Routledge \& Paul. 1952.

OSSIO A., Juan M. Guaman Poma: Nueva Coronica o Carta al Rey. Un Intento de Aproximación a las Categorías del Pensamiento del Mundo Andino. In: OSSIO, Juan (Ed.). Ideología Mesiánica del Mundo Andino: 155-213. Lima: Ignacio Prado Pastor. 1973.

- ¿Existen las poblaciones indígenas andinas en el Perú? In: FRANCH, José Alcina (Ed.). Indianismo e indigenismo en América: 162-189. Madrid: Sociedad Estatal Quinto Centenario/Alianza Editorial. 1990.

OWEN, Bruce. 2006. The 'vertical archipelago' model of Andean economics and settlement. Disponível em: <http://bruceowen.com/andeanae/326-06s05-Verticality.pdf>. Acesso em 30 de out. 2011.

PÄRSSINEN, Martti. La fortaleza de Oroncota y sus entornos. In: PÄRSSINEN, Martti; SIIRIÄINEN, Ari. Andes Orientales y Amazonía Occidental. Ensayos entre la historia y la arqueología de Bolivia, Brasily Perú: 169-211. La Paz: Universidad Mayor de San Andrés (UMSA)/Colegio Nacional de Historiadores de Bolivia/Producciones CIMA. 2003.

PÄRSSINEN, Martti; SIIRIÄINEN, Ari. [1998] 2003. Cuzcotoro y el sistema incaico de fortificaciones en Chuquisaca, Bolivia. In: PÄRSSINEN, Martti; SIIRIÄINEN, Ari. Andes Orientales y Amazonia Occidental. Ensayos entre la historia y la arqueología de Bolivia, Brasil y Perú: 133-165. La Paz: Universidad Mayor de San Andrés (UMSA) /Colegio Nacional de Historiadores de Bolivia/Producciones CIMA.

PLATT, Tristan. Symétries en mirroir. Le concept de yanantin chez les Macha de Bolivie. In: Annales ESC. v. 33, n. 5-6, p. 1081-1107. 1978.

. Estado boliviano y ayllu andino.Tierra y tributo en el norte de Potosí. Lima: Instituto de Estudios Peruanos. 1982. 
Limites turvos, objetos fugidios, identidades inconstantes...

. Entre ch'axwa y muxsa. Para una historia del pensamiento político aymara In: Thérèse Bouysse Cassagne et alii. Tres reflexiones sobre el pensamiento andino: 61132. La Paz: Hisbol. 1987.

PORTUGAL LOAYZA, Jimena. Los Yampara: Asentamientos Prehispánicos en alrededores de Sucre y Yotala. Sucre/La Paz: Fundación Acción Cultural Loyola (ACLO)/Universidad Mayor de San Andrés. 2006.

PRESTA, Ana María (Ed.). 1995. Espacio, Etnias, Frontera. Atenuaciones Politicas en el Sur del Tawantinsuyu. Siglos XV-XVIII. Sucre: Fundación Antropólogos del Surandino (ASUR).

RASNAKE, Roger Neil. 1988. Domination and Cultural Resistance. Authority and Power Among an Andean People. Durham: Duke University Press.

RIVERA CASANOVAS, Claudia. 2005. Sociedades Prehispánicas Tardías en los Valles Interandinos del Suroeste de Chuquisaca, Bolivia. In: Nuevos Aportes 3. Disponível em: <http://www.arqueobolivia.com/revistas/22_44_28-1142461390. pdf $>$. Acesso em: 30 de out. 2011.

RIVIÈRE, Gilles. 1983. Quadripartition et idéologie dans les communautés aymaras de Carangas (Bolivie). Em: Bulletin de l'Institut français d'études andines v. 12, n. 3-4, p. 41-62.

RÖSING, Ina. 1991. Introducción al mundo callawaya. Cochabamba: Editorial Los Amigos del Libro.

ROSTWOROWSKI T. DE DIEZ CANSECO, María. 1967. Etnohistoria de un valle costeño durante el Tahuantinsuyu. In: Revista del Museo Nacionalv. 35, p. 7-61. . 1977. Etnia y Sociedad. Costa peruana prehispánica. Lima: Instituto de Estudios Peruanos.

SAIGNES, Thierry. 1986. En busca del poblamiento étnico de los Andes bolivianos (siglos XV y XVI). La Paz: MUSEF (Museo Nacional de Etnografía y Folklore). (Avances de Investigación $\mathrm{n}^{\circ} 3$ ).

1985. Los Andes Orientales. Historia de un Olvido. Cochabamba: Centro de Estudios de la Realidad Económica y Social (CERES)/Hisbol/Institut français d'études andines (IFEA).

SALOMON, Frank. Andean ethnology in the 1970s: a retrospective. Em: Latin American Research Review v. 17, n. 2, 1982, p. 75-128.

SÁNCHEZ-ALBORNÓZ, Nicolás. 1978. Indios y tributos en el Alto Perú. Lima: Instituto de Estudios Peruanos. 


\section{Ricardo Cavalcanti-Schiel}

SCHRAMM, Raimund. 1993. Fronteras y territorialidad. Repartición étnica y política colonizadora en los Charcas (valles de Ayopaya y Mizque). In: Jabrbuch für Geschichte von Staat, Wirtschaft und Gesellschaft Lateinamericas. v. 30, p. 1-26. 1999. Pocona und Mizque. Die Umgestaltung einer indianischen Gesellschaft im

kolonialen Peru (Charcas). Colonia: Böhlau.

SOUZA, Marcela Coelho de. O traço e o círculo. O conceito de parentesco entre os jê e seus antropólogos. Rio de Janeiro: PPGAS - Museu Nacional - UFRJ. Tese (Doutorado). 2002.

VIVEIROS DE CASTRO, Eduardo B. Images of Nature and Society in Amazonian Ethnology. Annual Review of Anthropology v. 25, p. 179-200, 1996.

WACHTEL, Nathan. Les mitimas de la vallée de Cochabamba. La politique de colonisation de Huayna Capac. In: Jounal de la Société des américanistes. v. 67, 1981, p. 297-317.

. Le Retour des ancêtres. Les Indiens Urus de Bolivie XXe.-XVTe. siècle. Essai d'histoire régressive. Paris: Gallimard, 1990.

. Note sur le problème des identités collectives dans les Andes méridionales. In: L'Homme v. 32, n. 2-3-4, 1992, p. 39-52.

ZAVALA, Silvio A. La Encomienda Indiana. Madrid: Centro de Estudios Históricos. 1935.

Recebido em: 07/11/2011.

Aprovado em: 12/12/2011. 